\title{
Prognostic value of platelet to lymphocyte ratio in patients with non-small cell lung cancer
}

\author{
Mohammad Sabry Elkady, Ghada Refaat, Zeinab Elsayed, Kyrillus Farag* \\ Clinical Oncology Department, Faculty of Medicine, Ain Shams University, Cairo, Egypt
}

Received: January 9, 2019

Accepted: January 10, 2019

Online Published: January 16, 2019

DOI: $10.5430 /$ jst.v9n1p8

URL: https://doi.org/10.5430/jst.v9n1p8

\begin{abstract}
Background: The prognostic value of Platelet-to-lymphocyte ratio (PLR) in patients with non-small-cell lung cancer (NSCLC) is still indistinct. We conducted this study to assess the prognostic significance of pretreatment PLR in patients with unresectable NSCLC.

Aim of the Work: To assess the prognostic significance of pre-treatment PLR in patients with NSCLC.

Material and Methods: We retrospectively reviewed 130 patients treated for NSCLC with definitive/palliative chemotherapy and/or radiotherapy in Ain-Shams Universit hospital, Clinical Oncology department between January 2014 and December 2016. Pre-treatment CBC was available for the 130 patients to calculate PLR by dividing the absolute platelet count by the absolute lymphocytic count.

Results: Out of 130 patients with available pre-treatment complete blood picture, population age ranged from 23 to 87 years. Male to female ratio was $4.8: 1$. Adenocarcinoma presents $51 \%$ of cases. Unresectable stage II and stage III present $2 \%$ and $27 \%$ respectively, while Stage IV presents $69 \%$. Using a cut-off value of 150, a statistically significant correlation between baseline PLR $>150$ and presence of distant metastases was found $(p=.043)$; with a trend towards less advanced stage disease among group of patients with baseline PLR $<150(p=.064)$. High PLR $>150$ was significantly associated with poor overall survival (OS) (median OS: 10.33 months; 95\% CI: 6.23-14.42), compared to patients with PLR < 150; (median OS: 24.63 months, 95\% CI: 11.5-37.76, $p=.008$ ), but not PFS. In multivariate analysis, PLR $<150$ was an independent good prognostic factor for OS; $(\mathrm{HR}=0.549 ; 95 \%$ CI: 0.314-0.958; $p=.035)$.
\end{abstract}

Conclusion: High PLR is associated with poor OS in patients with unresectable NSCLC.

Key Words: Platelet to lymphocyte ratio, Non-small cell lung cancer, Prognostic factor

${ }^{*}$ Correspondence: Kyrillus Farag; Email: kyrillus.atef@gmail.com; Address: Clinical Oncology Department, Faculty of Medicine, Ain Shams University, Cairo, Egypt. 